\title{
RANCANG BANGUN PANEL KONTROL SELENOID VALVE SISTEM TERBUKA BERBASIS PROGRAM DAN MANUAL PADA UNTAI UJI BETA (UUB)
}

\author{
Kiswanta, Fitra Ramdhoni ${ }^{3}$ \\ 1,2,3 ProdiTeknikElektro FT UNPAM \\ Jln. Puspiptek Raya No 11Buaran, Tangerang Selatan 15310 INDONESIA
}

Fitra.unpam@gmail.com

\begin{abstract}
ABSTRAK
Untai Uji BETA (UUB) adalah sarana eksperimen yang dapat digunakan untuk mempelajari berbagai fenomena termohidroulika pada reaktor nuklir. Konfigurasi dasar UUB yaitu sistem pemanas (alat uji) dan sistem sirkulasi air. Rancangan dibuat untuk mengatur sistem sirkulasi air pada UUB dengan menggunakan sistem program dan manual yang mengatur selenoid valve. Metode yang telah dilakukan meliputi: (1) Perancangan sistem program dan manual yang mengatur selenoid valve. (2) Pembuatan sistem program menggunakan PLC melalui Programming Console. (3) membuat desain panel dilanjutkan dengan perakitan. (5) Pembuatan prosedur pengoperasian panel. (6) Tahap pengujian panel dan selenoid valve. Kesimpulan: sistem manual dibuat diluar aturan yang dibuat sistem program untuk mengatur selenoid valve.
\end{abstract}

Kata kunci :UntaiUji BETA (UUB), sirkulasi air, sistem program dan manual, PLC, Programming console, Selenoid Valve.

\begin{abstract}
BETA test strand (UUB) is a means of experiments that can be used to study various phenomena thermal hydroulic in nuclear reactors. The basic configuration is UUB heating system (test equipment) and a water circulation system. Automation is made to regulate water circulation system in UUB using manual systems and programs that govern the solenoid valve. Methods that have been made include: (1) The design of the program and manual systems that regulate the solenoid valve. (2) Making use of the PLC system program through the Programming Console. (3) making the design panel followed by the assembly. (5) Preparation of operating procedures of the panel. (6) The testing phase panel and solenoid valve. Conclusion: the system manually created rules that were made outside the system for regulating solenoid valve program.
\end{abstract}

Keywords :String Test BETA (UUB), water circulation, program and manual systems, PLC, Programming console, Selenoid Valve.

\section{PENDAHULUAN}

usat

TeknologiReaktordanKeselamatanNuk lir (PTRKN) adalahsalahsatulembagapenelitianpengemb angankeselamatanreaktordannuklir bawahBadanTenagaNuklirNasional
(BATAN)

yang mempunyaitugasuntukpenelitiandanpengem banganreaktornuklir agar amandanselamatseiringdenganperkembang anteknologi BATAN. Salah satualat yang digunakansebagai media eksperimensimulasireaktornuklirdinamakan denganUntaiUji BETA 
(UUB).Konfigurasidasar adalahsistemsirkulasi menggunakanpipa-pipa salingterhubung, pemanaslistriksebagaipengganti uranium padaPembangkitListrikTenagaNuklir

(PLTN), dansistempembuanganpanas. Untukmempelajariberbagaifenomenathermo hidraulikatersebut, UUB dilengkapidenganberbagaibagianuji (test section) diantaranyaHeaTiNG-02, QUEEN02 dan lain lain. Seperti yang telahdiketahui, padabagiankonfigurasidasarUntaiUji BETA (UUB) yaitusistemsirkulasi air antarabagianbagianpada UUB denganmenggunakanpipa-pipa yang salingterhubung.Bagianbagiantersebutdiant aranyaalatuji, heater, kondensor, pompa air danmasihbanyaklagi.Sistemsirkulasi air padapipa-pipa yang terdapatpadaUntaiUji BETA hanyasebatasmenggunakankeran air manual untukpengoperasiannya.Hal inidapatmembuathasileksperimenpadaUntai Uji BETA (UUB) menjaditidakakuratkarenabutuhwaktuuntuk membukabeberapakeran manual saatdilakukannyaeksperimen.

PadaSkripsiini,

Penulisinginmembuatsuaturangkaian kontrolkeran dapatmengatursistemsirkulasi yang padaUntaiUji BETA (UUB) agar eksperimen yang dilakukanpada UUB dapatberjalanlebihmudahdanefisiensipada UUB dapatditingkatkan.

\section{TEOR।}

\section{UntaiUji BETA (UUB).}

Untaiujitermohidrolika BETA (Boucle d"experimentTermohidrolika Applique) UUB adalahsaranaeksperimen yang dapatdigunakanuntukpenelitiandanpemaha manfenomenareflooding yang terjadipada bundle bahanbakar PWR selamapascaLOCA. Riset yang dilakukanpada UUB ditunjukanselainuntukpemahamanfenomena melaluipengamatanlangsung,

adalahjugamemperoleh

data komparasi.UUB jugadapatdigunakanuntukeksperimenataupe nelitianpengembanganteknologikeselamata
nreaktorpadaPembangkitListrikTenagaNukli

$r$ (PLTN).Konfigurasidasar UUB

adalahsistemsirkulasi

air

menggunakanpipa-pipa

salingterhubung,

pemanaslistriksebagaipengganti uranium padaPembangkitListrikTenagaNuklir

(PLTN), dansistempembuanganpanas.

Sebagaisistem

yang

digunakandalameksperimen,

tentusajaUntaiUji BETA

memilikikomponen-komponenataubagian-

bagiandidalamnya, bagian-bagianpenting yang terdapatpadaUntaiUji BETA (UUB) diantaranya,

panel utamalistrikuntuksemuabagianuntaiuji beta, trafo regulator, panel distribusilistrikuntukalatuji,

tangkipenampung air, pompa air primer, pompa air sekunder, flow meter, pre-heater, panel kontrolsuhuuntuk pre-heater, kondensor, tangki air pembuangpanas (kondensor), ECWS (equipment cooling water system), pipa-pipasirkulasiuntuk air, alatujipemanaslistrik (QUEEN-01, QUEEN02, HeaTiNG-01, HeaTiNG-02, HeaTiNG03), termokopel, DAS (data akuisisisistem), dankomputerbeserta software yang akandigunakandalameksperimen.

BerikutgambarskematikdariUntaiUji BETA (UUB).

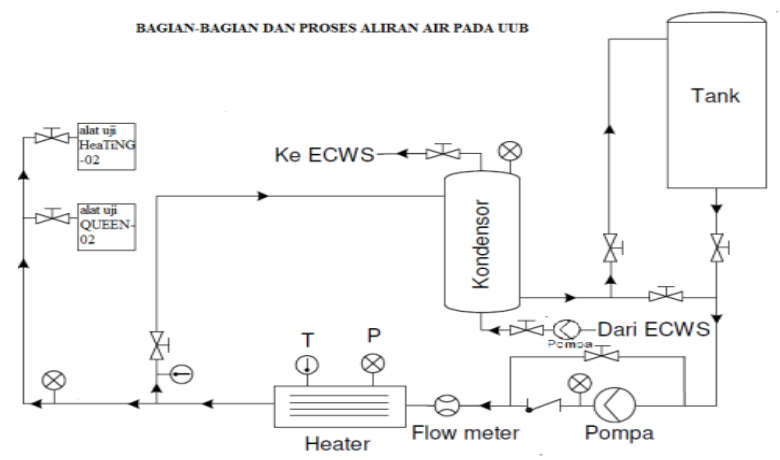

Gambar 1.Aliransirkulasi air padaUntaiUji Beta (UUB).

Sistem Open Loop, Program dan Manual.

$\begin{array}{lcr}\text { Sistem } & \text { open } & \text { loop } \\ \text { yaitutidakadanyatimbalbalikantara } & \text { output } \\ \text { dan } \quad \text { input } & \text { atau } & \text { output }\end{array}$ tidakberpengaruhterhadapaksipengontrolan (input). Seperti yang telahdiketahuisistem 
open loop adalahsistemkendali yang dilakukandimanasuatu output tidakmemberikanefekterhadapbesaran input, sehinggavariabel yang dikendalikantidakdapatdibandingkandengan harga yang diinginkan.

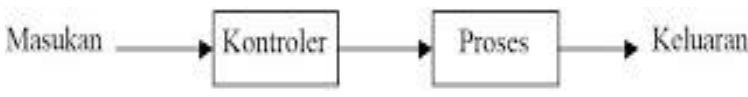

Gambar 2.Sistemkontrol open loop.

Dilihatdarigambardiatasmakadapatdijelaska $\mathrm{n}$ :

Masukanadalahperintah yang diberikanpadarangkaianuntukmemulaisuatu systemyang

besarannyadiubahsehinggadapatdigunakan olehsistem. Padakasus kali inimasukanmenggunakansaklar yang berfungsimengaktifkansistem.

Kontroleradalahbagian yang menerimaperintahdarimasukandanmerubah perintahtersebut agar dapat di proses padabagianselanjutnya.

Proses adalahbagian yang memproses data darikontrolersehinggadapatditeruskanmenuj ukeluaran.

Sistem program adalah perangkat lunak sistem yang bertugas untuk melakukan kontrol dan manajemen perangkat keras serta operasi-operasi dasar sistem, atau dengan kata lain program sistem adalah software pada lapisan pertama yang disimpan pada memori perangkat hardware (dalam hal ini menggunakan PLC) dan merupakan program pertama yang dijalankan pada saat hardware dinyalakan. Program sistem sering juga disebut sistem operasi.

Sistem Pengendalian Manual/Konvensional adalah sistem pengendalian dengan subyek adalah makhluk hidup, contoh oleh manusia. Biasanya sistem ini dipakai pada beberapa proses-proses yang tidak banyak mengalami perubahan beban (load) atau pada proses yang tidak kritis.

\section{PLC (Programmable Logic Control).}

PLC merupakanperangkat yang dirancanguntukmenggantikansistemkontrolk onvensional.PLC pertama kali dirancangolehperusahaan General Motor (GM) sekitartahun $1968 . \quad$ Ide utamanyaadalahmensubtitusi relay yang digunakanuntukmengimplementasikanrangk aiankontrol.

PLC secara bahasa berarti pengontrol logika yang dapat diprogram. Dengan kata lain, PLC merupakan sistem peralatan yang digunakan untuk mengontrol sistem peralatan atau sistem lain menggunakan suatu rangkaian logika yang dapat diprogram sesuai kebutuhan. PLC menyerupai komputer elektronik yang mudah digunakan (user friendly) yang memiliki fungsi kendali untuk berbagai tipe dan tingkat kesulitan yang beraneka ragam.

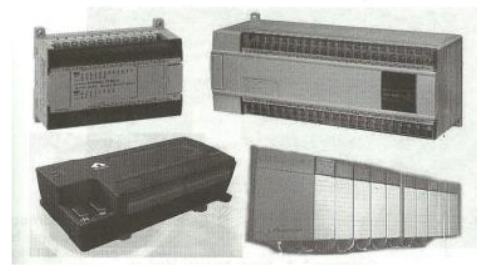

Gambar 3. Contoh fisik PLC

Untuk menyelesaikan permasalahan dalam bidang teknik kendali, dapat direalisasikan dengan mudah menggunakan PLC. Komponen-komponen PLC yang diperlukan untuk sistem kendali diantaranya berupa Central Controller Unit (CCU) yang disebut dengan istilah Central Processing Unit (CPU) yang terdiri dari Processor, Memory dan Power Supply serta bagian Input/Output (I/O) Strructure dan Program Device.

Pada kesempatan ini, penulis menggunakan PLC merk Omron dengan tipe CPM-1A.

\section{Handheld Programming Console.}

Handheld programmer PLC (programming console) adalah sebuah alat yang digunakan untuk membuat program PLC yang nantinya program tersebut di transfer kedalam PLC. Sistem program yang dibuat berbentuk mnemonic code. Pada pekerjaan kali ini, dapat kita lihat salah satu programming console dari merk omron jenis PRO 01. 


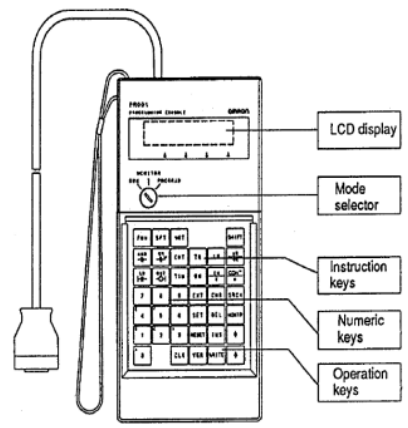

Gambar 4. Model Programming Console PLC Merk Omron.

Berdasarkan gambar 4,dapat dijelaskan jenis dan fungsi dari masing-masing bagian atau tombol (posisi) yang terdapat pada console, meliputi :

- PROGRAM digunakan untuk membuat program atau memodifikasi program atau memperbaiki program yang sudah ditulis.

- MONITOR digunakan untuk mengubah nilai settingan dari counter dan timer yang dapat dilakukan pada saat PLC sedang dalam keadaan beroprasi (running).

- RUN digunakan untuk mengoprasikan program yang sudah ditulis tanpa mengubah nilai setting sebagaimana dapat diubah pada posisi monitor.

- FUN digunakan untuk memanggil fungsi yang diinginkan yang dilakukan dengan cara menekan tombol ini, diikuti dengan menekan dua tombol ( dua digit) dengan nomor fungsi yang dikehendaki.

- LD, LoaD berfungsi sebagai tombol masukkan (input) yang diinginkan sebagai bagian awal dari ladder diagram.

- AND, berfungsi sebagai input yang diserikan dengan input sebelumnya.

- OR, berfungsi sebagai input yang di paralel dengan input sebelumnya.

- OUT, berfungsi sebagai output dari rangkaian ladder diagram yang dibuat.

- TIM, berfungsi sebagai input timer (pewaktu) yang dapat disetting dan digunakan sebagai input atau sebagai output.

- CNT, berfungsi sebagai penghitung dan dapat digunakan sebagai input ataupun output.

- NOT, dapat digunakan bergandengan dengan LD, AND atau OR dengan fungsi sebagai kontak NC. Jika digunakan dengan output maka berfungsi sebagai output invers dan input invers.
- HR, berfungsi untuk mendefinisikan holding relay.

- TR, berfungsi untuk mendefinisikan temporary relay.

- SFT, berfungsi untuk menampilkan operasi shift register.

- SHIFT, digunakan sebagai fungsi pengganti dari empat tombol dengan kegunaan lebih dari satu, tertulis PLAY, RECORD, Chanel CONTact.

- 0-9, digunakan sebagai input berupa angka desimal dan hexadesimal pada saat pemrogramman.

\section{Selenoid Valve.}

Solenoid valve adalah katup yang digerakan oleh energi listrik, mempunyai kumparan sebagai penggeraknya yang berfungsi untuk menggerakan piston yang dapat digerakan oleh arus AC maupun DC, solenoid valve atau katup (valve) solenoida mempunyai lubang keluaran, lubang masukan dan lubang exhaust, lubang masukan, berfungsi sebagai terminal / tempat cairan masuk atau supply, lalu lubang keluaran, berfungsi sebagai terminal atau tempat cairan keluar yang dihubungkan ke beban, sedangkan lubang exhaust, berfungsi sebagai saluran untuk mengeluarkan cairan yang terjebak saat piston bergerak atau pindah posisi ketika solenoid valve bekerja.

Selenoid valve yang akan digunakan pada tugas akhir ini mempunyai tipe Normally Close (NC). Yaitu valve akan membuka dan mengalirkan cairan hanya pada saat diberi tegangan atau arus listrik. Selenoid valve ini akan digunakan sebagai beban atau output pada rangkaian yang akan dibuat.

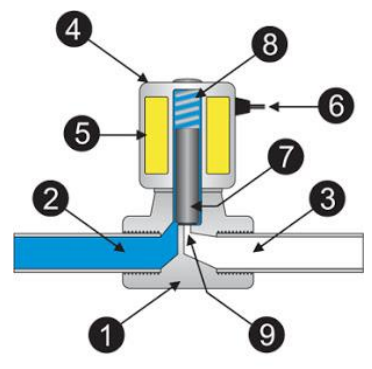

Gambar 5 Struktur fungsi selenoid valve.

Keterangan Gambar :

1. Valve Body

2. Terminal masukan (Inlet Port)

3. Terminal keluaran (Outlet Port) 
4. Koil / koil solenoid

5. Kumparan gulungan

6. Kabel suplai tegangan

7. Plunger

8. Spring

9. Lubang / exhaust

\section{METODOLOGI}

\section{TAHAPAN PEKERJAAN.}

1. Memahami sistem kerja dari alat uji eksperiment UUB (Untai Uji BETA).

2. Membuat sistem kerja berbentuk flow chart atau diagram bagan baik dari sisi program dan manual operational pada panel kontrol sesuai perintah dan kebutuhan.

3. Mempersiapkan alat dan bahan yang diperlukan untuk membuat panel kontrol serta pengaplikasian pada alat uji UUB.

4. Membuat ladder diagram untuk di aplikasikan pada program PLC sesuai skema yang direncanakan.

5. Input program pada PLC menggunakan programming console Omron.

6. Merakit panel kontrol sesuai sistem kerja yang direncanakan.

7. Mengimplementasikan panel kontrol pada alat uji eksperiment UUB.

8. Menganalisa, menyimpulkan serta memberi saran tambahan pada panel kontrol agar rangkaian tidak mendapatkan masalah di kemudian hari.

\section{HASIL DAN PEMBAHASAN}

\section{Perencanaan Sistem Kerja.}

Pada rencana sistem kerja, terbagi menjadi 2 , pertama adalah sistem program pada PLCperistiwa dibuat menjadi tiga kejadian yaitu kejadian sirkulasi air by-pass, sirkulasi air menuju Heating-02 dan sirkulasi air menuju Queen-02. Saat program dimulai, sirkulasi air by-pass yang akan terjadi pada sistem. Selanjutnya kita harus memilih alat uji mana yang akan digunakan dalam eksperimen. Pada program PLC, dibuat suatu kejadian dimana jika kita menginginkan eksperiment dilakukan pada alat uji Heating-02 maka alat uji queen 2 tidak akan dapat dioperasikan, kita hanya dapat memilih salah satu dari alat uji yang akan digunakan, begitupun sebaliknya. Tetapi jika kedua kejadian tidak diaktifkan, maka sistem akan kembali menuju titik awal dimana sirkulasi air kembali ke by-pass.

Untuk lebih jelasnya dapat kita lihat pada flowchart rangkaian program di bawah ini.

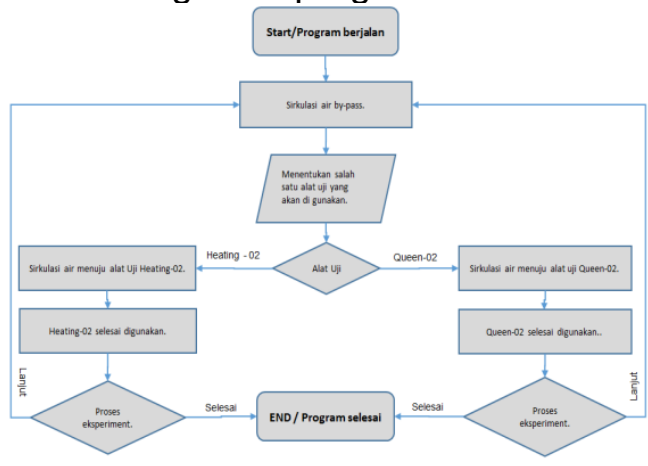

Gambar 6.Flow chart sistem program.

Atas dasar flow chart di atas, maka dapat dibuat skema diagram bagan PLC berikut.

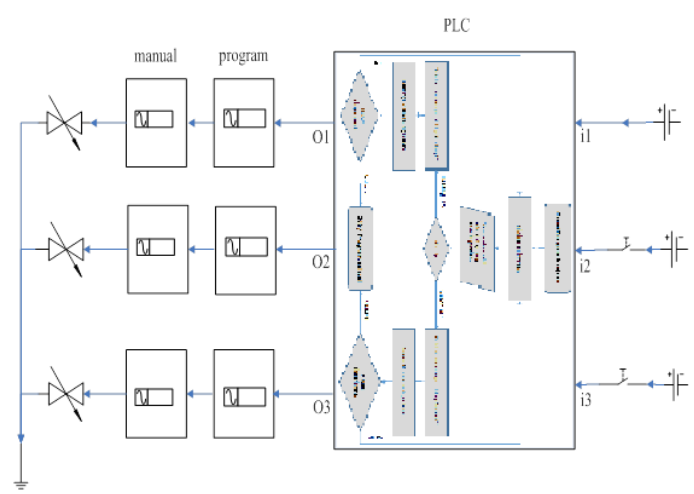

Gambar 7. Diagram bagan rangkaian.

Dari gambar diatas, dapat kita simpulkan, input PLC terdiri dari 3 input untuk mengatur 3 kejadian pada output (selenoid valve). Output PLC akan memberikan sinyal kepada relay output program.

Selanjutnya sistem kedua adalah sistem manual. Sistem manual bekerja diluar perintah dari flowchart yang sudah di atur pada PLC, output (selenoid valve) dapat diatur untuk aktif atau tidaknya secara bebas tanpa ada batasan perintah dari sistem program PLC. Oleh karena itu, dapat kita lihat pada diagram bagan diatas, relay manual ditempatkan setelah relay program sebelum sinyal masuk pada output (selenoid valve).

\section{Alat yang diperlukan :}

- PLC OMRON CPM1A, 
- Programming Console Pro 01,

- Multi tester merk SANWA yx360 trf,

\section{Bahan yang diperlukan:}

- Contact relay 220 Vacdan socket 3 buah,

- Contact relay 24 Vdcdan socket 3 buah,

- Box panel denganukuran. Box panel terbuatdaribajadengantebal $\quad 1,5 \mathrm{~mm}$ berlapis cat oven warnaabu-abu,

- MCB 2 Ampere 1 buah,

- Lampuindikator led 220 Vac 3 buah.

- Lampuindikator 220 Vac 3 buah,

- Lampu indicator led 24 Vdc 3 buah,

- Saklartunggal 5 buah,

- Kabeltembagadenganisolasiwarnaputih 25 meter,

- Kabeltembagadenganisolasiwarnabiru 25 meter,

- Pembungkuskabel spiral 1 meter,

- Cable duct 2 meter,

- Terminalkabel 1 buah,

- Plat yang digunakan untuk dudukan komponen 1 meter,

- Lem bakar 1 buah,

- Baut, skrup, dan mur secukupnya.

\section{Tahap Perakitan Panel Kontrol.}

1. Membuat ladder diagram dan input program ke dalam PLC Omron CPM1A menggunakan programming console Pro01.

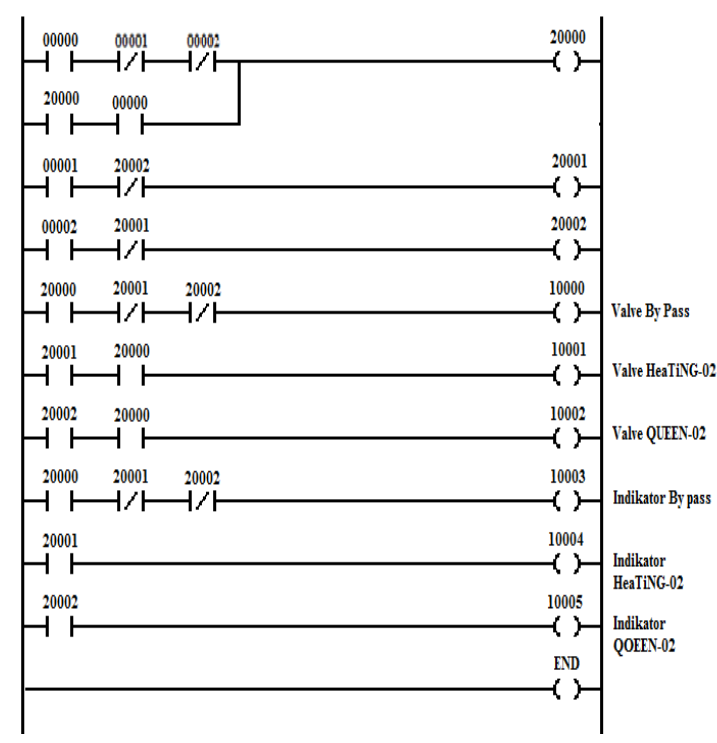

Gambar 8. Ladder diagram PLC (sistem program).

Ladder yang sudah dibuat sesuai prinsip kerja sistem program yang sudah direncanakan selajutnya masukkan satu persatu instruksi instruksi mnemonic codes ladder pada programming console dengan perintah pada tabel berikut.

Tabel 1 Proses input perintah pada programming console.

\begin{tabular}{|l|l|}
\hline Instruksi 1 & CLR - MONTR - CLR \\
\hline instruksi 2 & LOD - 00000 - WRITE \\
\hline Instruksi 3 & AND - NOT - 20002 - WRITE \\
\hline Instruksi 4 & LOD - 20000 - WRITE \\
\hline Instruksi 5 & AND - 00000 - WRITE \\
\hline Instruksi 6 & OR - LOD - WRITE \\
\hline Instruksi 7 & OUT - 20000 - WRITE \\
\hline Instruksi 8 & LOD - 00001 - WRITE \\
\hline Instruksi 9 & AND - NOT - 20002 - WRITE \\
\hline Instruksi 10 & OUT - 20001 - WRITE \\
\hline Instruksi 11 & LOD - 00002 - WRITE \\
\hline Instruksi 12 & AND - NOT - 20001 - WRITE \\
\hline Instruksi 13 & LOD - 20000 - WRITE \\
\hline Instruksi 14 & AND - NOT - 20001 - WRITE \\
\hline Instruksi 15 & AND - NOT - 20002 - WRITE \\
\hline Instruksi 16 & OUT - 10000 - WRITE \\
\hline Instruksi 17 & LOD - 20001 - WRITE \\
\hline Instruksi 18 & AND - 20000 - WRITE \\
\hline Instruksi 19 & OUT - 10001 - WRITE \\
\hline Instruksi 20 & LOD - 20002 - WRITE \\
\hline Instruksi 21 & AND - 20000 - WRITE \\
\hline Instruksi 22 & OUT - 10002 - WRITE \\
\hline Instruksi 23 & LOD - 20000 - WRITE \\
\hline Instruksi 24 & AND - NOT - 20001 - WRITE \\
\hline Instruksi 25 & AND - NOT - 20002 - WRITE \\
\hline Instruksi 26 & OUT - 10003 - WRITE \\
\hline Instruksi 27 & LOD - 20001 - WRITE \\
\hline Instruksi 28 & OUT - 10004 - WRITE \\
\hline Instruksi 29 & LOD - 20002 - WRITE \\
\hline Instruksi 30 & OUT - 10005 - WRITE \\
\hline Instruksi 31 & FUN - 0 - 1 - WRITE \\
\hline
\end{tabular}

2. Pemasangan bahan-bahan yang sudah disiapkan (PLC, relay, dan lain lain) pada box panel dengan mengikuti wirring diagram keseluruhan panel kontrol sebagai berikut.

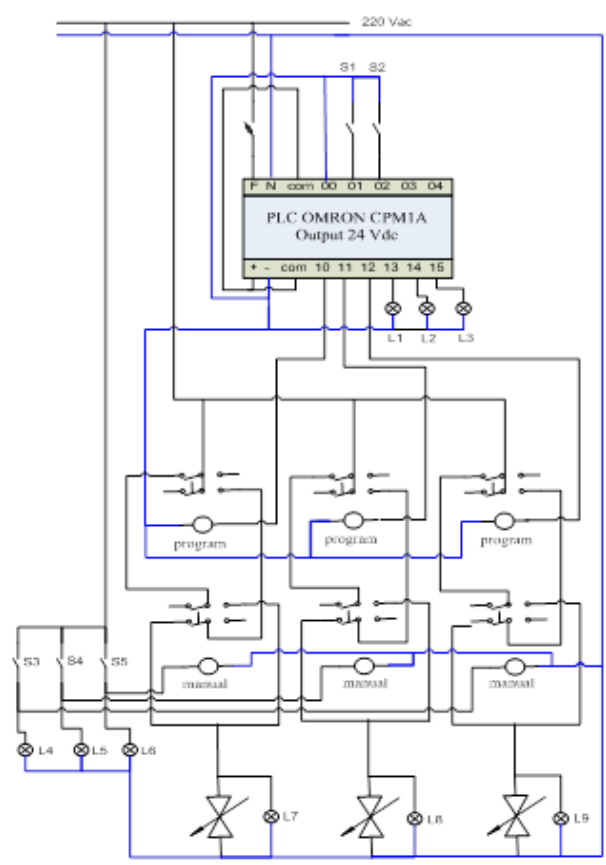


Gambar 9. Wirring diagram keseluruhan panel kontrol.

Setelah semua terpasang dan panel kontrol tidak lupa untuk menjaga estetika kerapihan serta keamanan pada panel agar tidak membahayakan pengguna saat mengoperasikan panel kontrol.

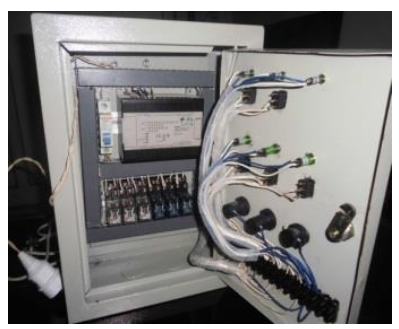

Gambar 10. Panel kontrol setelah perakitan.

Setelah dirasa panel cukup baik untuk dapat digunakan, tahap selanjutnya adalah memberi label, wiring dan petunjuk operasional pemakaian pada bagian pintu panel agar pengguna tidak bingung saat ingin mengoperasikan panel kontrol tersebut.

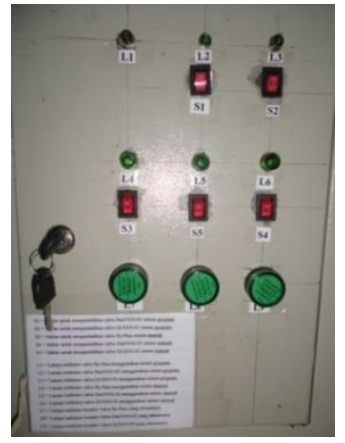

Gambar 11.Komponen yang sudah diberi simbol dan keterangan pada pintu panel

Tabel 2. Simbol dan arti dari masing-masing komponen.

\begin{tabular}{|c|l|}
\hline Simbol & \multicolumn{1}{|c|}{ Keterangan } \\
\hline S1 & Saklar untuk mengendalikan valve HeaTiNG-02 sistem program. \\
\hline S2 & Saklar untuk mengendalikan valve QUEEN-02 sistem program. \\
\hline S3 & Saklar untuk mengendalikan valve By-Pass sistem manual. \\
\hline S4 & Saklar untuk mengendalikan valve HeaTiNG-02 sistem manual. \\
\hline S5 & Saklar untuk mengendalikan valve QUEEN-02 sistem manual. \\
\hline L1 & Lampu indikator valve By-Pass menggunakan sistem program. \\
\hline L2 & Lampu indikator valve HeaTiNG-02 menggunakan sistem program. \\
\hline L3 & Lampu indikator valve QUEEN-02 menggunakan sistem program. \\
\hline L4 & Lampu indikator valve By-Pass menggunakan sistem manual. \\
\hline L5 & Lampu indikator valve HeaTiNG-02 menggunakan sistem manual. \\
\hline L6 & Lampu indikator valve QUEEN-02 menggunakan sistem manual. \\
\hline L7 & Lampu indikator kondisi Valve By-Pass yang sebenarnya. \\
\hline L8 & Lampu indikator kondisi Valve HeaTiNG-02 yang sebenarnya. \\
\hline L9 & Lampu indikator kondisi Valve QUEEN-02 yang sebenarnya. \\
\hline
\end{tabular}

Setelah semua simbol, petunjuk operational, wiring diagram dan simbol komponen sudah terpasang, kita lanjutkan pada tahap pengujian dan hasil untuk mengetahui performa panel kontrol dan tidak terjadi kesalahan pada saat digunakan kedepannya.

\section{PENGUJIAN DAN HASIL}

Untuk mendapatkan hasil dan pembahasan, maka penulis melakukan beberapa tahap pengujian pada panel kontrol. Pengujian tersebut dilakukan agar tidak terjadi kesalahan saat panel kontrol diimplementasikan pada alat uji Untai Uji BETA (UUB). Pengujian disini meliputi pengujian sistem program, pengujian sistem manual, pengujian hubungan antara sistem program dan manual.

\section{Pengujian dan Hasil Sistem Program.}

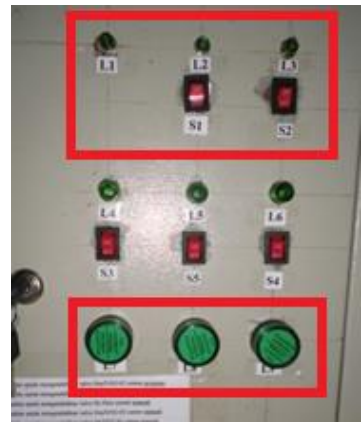

Gambar 12.Pengujiansistem program.

Dapat kita lihat pada gambar 12 , pada bagian yang diberi tanda adalah perangkat komponen yang akan diuji dan berhubungan dengan pengujian sistem 
program (sistem manual diabaikan). Untuk item pengujian dan hasil dapat kita lihat pada tabel berikut.

Tabel 3. Hasil Pengujian sistem program.

\begin{tabular}{|c|c|c|c|c|c|c|c|c|c|c|c|c|c|c|c|}
\hline \multirow{3}{*}{$\begin{array}{l}\text { Tahap } \\
\text { pengujian }\end{array}$} & \multirow{2}{*}{\multicolumn{3}{|c|}{ Kondisi Input }} & \multicolumn{12}{|c|}{ Kondisi Lampu Indikator } \\
\hline & & & & \multicolumn{6}{|c|}{ Rencana Dari Sistem } & \multicolumn{6}{|c|}{ Hasil Pengujian } \\
\hline & MCB & S1 & S2 & \begin{tabular}{l|l} 
L1 & \\
\end{tabular} & \begin{tabular}{l|l}
$\mathrm{L} 2$ & $\mathrm{~L}$ \\
\end{tabular} & L3 & L7 & & & 11 & L2 & L3 & L7 & L8 & L9 \\
\hline 1 & Off & Off & Off & & & & & & & & & & & & \\
\hline 2 & On & Off & Off & & & & & & & & & & & & \\
\hline 3 & On & On & Off & & & & & & & & & & & & \\
\hline 4 & On & On & On & & & & & & & & & & & & \\
\hline 5 & On & Off & On & & & & & & & & & & & & \\
\hline 6 & On & On & On & & & & & & & & & & & & \\
\hline Ket : & $\mathrm{Hid}$ & & $M_{i}$ & & & & & & & & & & & & \\
\hline
\end{tabular}

Berdasarkan dari tabel diatas, hasil dari pengujian sistem program sesuai dengan rencana yang sudah dibuat dikarenakan lampu indikator hasil pengujian berbanding lurus dengan rencana yang sudah dibuat. Pembahasan dari pengujian ini yaitu, sistem dibuat interlock antara input S1 dan S2 sebelum keadaan dikembalikan pada tahap pengujian nomor 2 .

\section{Pengujian dan Hasil Sistem Manual.}

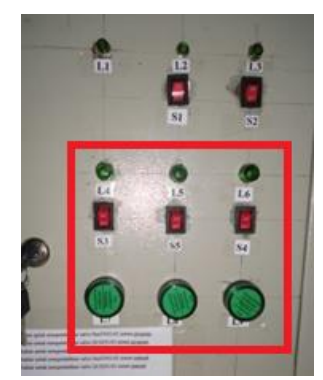

Gambar 13.Pengujian komponen dari sistem manual.

Dapat kita lihat pada gambar 13 , pada bagian yang diberi tanda adalah perangkat komponen yang akan diuji dan berhubungan dengan pengujian sistem manual (sistem program diabaikan). Untuk item pengujian dan hasil dapat kita lihat pada tabel berikut.

Tabel 4. Pengujian dan hasil sistem manual

\begin{tabular}{|c|c|c|c|c|c|c|c|c|c|c|c|c|c|c|c|c|}
\hline \multirow{3}{*}{$\begin{array}{c}\text { Tahap } \\
\text { pengujian }\end{array}$} & \multirow{2}{*}{\multicolumn{4}{|c|}{ Kondisi Input }} & \multicolumn{12}{|c|}{ Kondisi Lampu Indikator } \\
\hline & & & & & \multicolumn{6}{|c|}{ Rencana Dari Sistem } & \multicolumn{6}{|c|}{ Hasil Pengujian } \\
\hline & MCB & S3 & S4 & S5 & L4 & L5 & L6 & L7 & L8 & L9 & L4 & $\mathrm{L} 5$ & L6 & L7 & L8 & L9 \\
\hline 1 & Off & Off & Off & Off & & & & & & & & & & & & \\
\hline 2 & On & Off & Off & Off & & & & & & & & & & & & \\
\hline 3 & On & On & Off & Off & & & & & & & & & & & & \\
\hline 4 & On & On & On & Off & & & & & & & & & & & & \\
\hline 5 & On & On & On & On & & & & & & & & & & & & \\
\hline 6 & On & On & On & On & & & & & & & & & & & & \\
\hline Ket : & \multicolumn{2}{|c|}{ Hidup } & \multicolumn{2}{|c|}{ Mati } & & & & & & & & & & & & \\
\hline
\end{tabular}

Berdasarkan dari tabel diatas, hasil dari pengujian sistem program sesuai dengan rencana yang sudah dibuat dikarenakan lampu indikator hasil pengujian berbanding lurus dengan rencana yang sudah dibuat. Pembahasan dari pengujian ini yaitu sistem manual dapat dioperasikan sesuai kemauan dari pengguna atau dengan kata lain tidak ada batasan untuk mengoperasikan laju air pada alat uji eksperiment untai uji BETA.

\section{Pengujian dan hasil dari hubungan antara sistem program dan manual.}

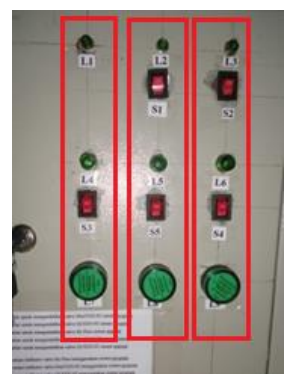

Gambar 14 Pengujian gabungan antara kedua sistem (program dan manual).

Setelah kita mengetahui fungsi dari masingmasing switch dan lampu indikator dari pengujian sebelumnya, kita lanjutkan tahapan pengujian untuk mengetahui hubungan antara kedua sistem (program dan manual) dengan melihat tabel berikut. 
Tabel 5. Pengujian gabungan sistem program dan manual.

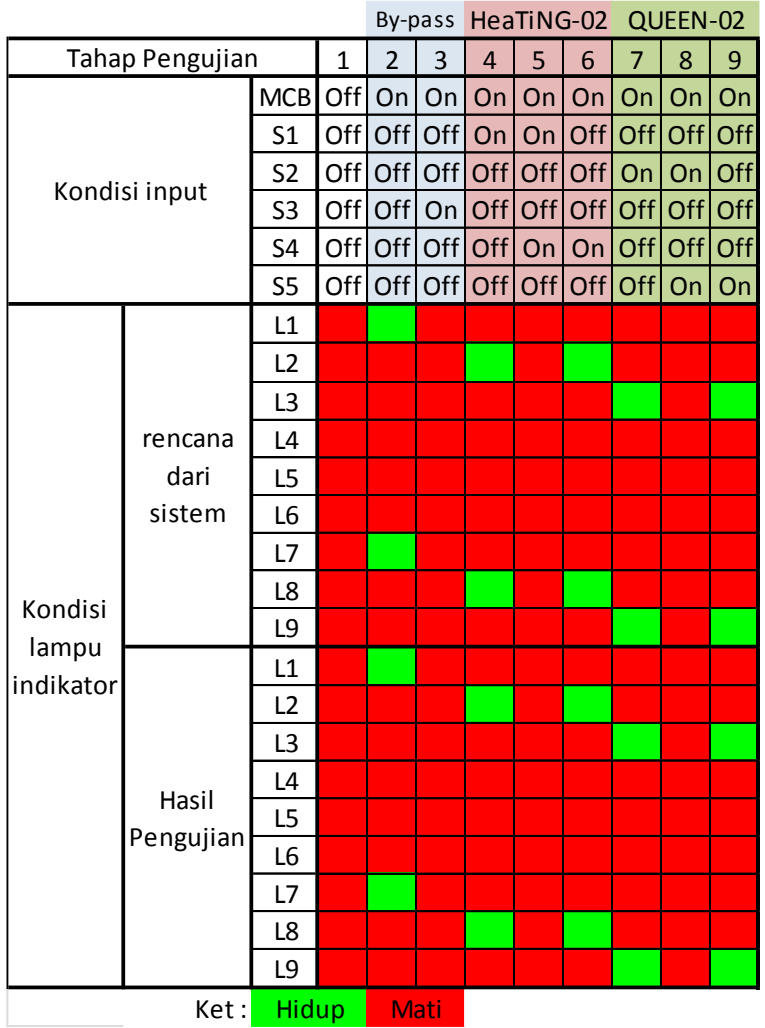

Berdasarkan dari tabel diatas, hasil dari pengujian sistem program sesuai dengan rencana yang sudah dibuat dikarenakan lampu indikator hasil pengujian berbanding lurus dengan rencana yang sudah dibuat. Pembahasan dari pengujian ini yaitu, sistem manual berperan saat terjadi keadaaan dimana kita menginginkan hasil output selenoid diluar dari sistem program yang sudah direncanakan. Berikut tabel yang menerangkan secara singkat bagaimana sistem manual dapat berperan untuk hasil dari output yang diatur oleh sistem program.

Tabel 6. Hubungan sistem manual dengan sistem program.

\begin{tabular}{|c|c|c|c|}
\hline No & Sistem Program & Sistem Manual & Output selenoid valve \\
\hline 1 & 0 & 0 & 0 \\
\hline 2 & I & 0 & I \\
\hline 3 & 0 & I & I \\
\hline 4 & I & I & 0 \\
\hline
\end{tabular}

\section{KESIMPULAN}

Setelah semua tahap pembuatan rancang bangun panel kontrol selenoid valve sistem terbuka berbasis program dan manual pada Untai Uji BETA (UUB) telah selesai dilakukan. Dimulai dari tahap perancangan, pebuatan, pengujian sampai hasil dan pembahasan. Maka dapat dibuat kesimpulan dari penelitian ini. Kesimpulankesimpulan tersebut adalah.

1. Panel kontrol dibuat untuk mengatur selenoid valve yang digunakan untuk menggantikan valve manual pada alat uji eksperiment Untai Uji BETA (UUB) menggunakan sistem terbuka berbasis program dan manual yang dirakit dengan alat alat elektronik dan elektrikal.

2. Sistem program menggunakan PLC sebagai objek pada panel kontrol dengan beberapa aturan yang sudah ditentukan, sistem manual menggunakan relai $A C$ dan DC sebagai kontrolnya.

3. Prinsip kerja sistem program PLC adalah saat panel kontrol aktif, selenoid valve diatur langsung mengalirkan air pada sirkulasi by-pass pada UUB, saat kondisi seperti ini, terdapat 2 opsi apakah kita akan menggunakan alat uji QUEEN-02 atau HeaTiNG-02 pada alat uji eksperimen. Kita hanya dapat memilih satu dari 2 opsi tersebut, terkecuali kita kembalikan posisi kembali pada sirkulasi by-pass. Untuk sistem kerja manual di atur dengan tidak terpengaruh pada aturan sistem program dan berfungsi jika ada kegiatan yang akan dilakukan diluar dari sistem program PLC.

\section{DAFTAR PUSTAKA}

[1] PengertianPemrogramanSistemdanJeni sSistemOperasiKomputasidan Mobile diambildarihttp://sentrablog.blogspot.co m/2011/02/tugas-pemrog-sistempengertian.html diaksespadatanggal 15 Oktober 2013

[2] PrinsipKerjaSelenoid Valve diambildarihttp://www.meriwardanaku.c om/2011/11/solenoid-

valve.htmldiaksespadatanggal 20

Oktober 2013

[3] Apriyanto, Yayang,

PembuatanSistemInstrumentasidanKon trolBerbasis Programmable Logic Controller (PLC) Pada USSA-FT01, JurusanTeknikFisika, IbnKhaldun, Bogor, 2010

[4] Said, Hanif, Aplikasi Programmable Logic Controller (PLC) 
danSistemPneumatikPadaManufakturln dustri, Yogyakarta 2005

[5] Ramdhoni, Fitra,

PengembanganSistemPemanasListrik

HeaTtiNG-02 Pada UNTAI UJI BETA

(UUB),

PusatTeknologiReaktordanKeselamata nNuklir (PTRKN), UniversitasPamulang, Tangerang Selatan, 2013

[6] Suhendar, Programmable Logic Control, Grahallmu, Yogyakarta, 2005 